\title{
Shift of glycaemic thresholds for cognitive function in hypoglycaemia unawareness in humans
}

\author{
C. G. Fanelli, S. Pampanelli, F. Porcellati, G. B. Bolli \\ Department of Internal Medicine, Endocrinology and Metabolism, University of Perugia, Perugia, Italy
}

The glycaemic thresholds at which physiological responses to hypoglycaemia are initiated, are now wellestablished in non-diabetic subjects [1,2]. During a hyperinsulinaemic-hypoglycaemic stepped clamp, the glycaemic threshold for hormone release ranges between 3.6 to $3.8 \mathrm{mmol} / \mathrm{l}(65-68 \mathrm{mg} / \mathrm{dl})$, that for symptom appearance is approximately $3.0 \mathrm{mmol} / \mathrm{l}(54 \mathrm{mg} /$ $\mathrm{dl}$ ), and that for onset of cognitive dysfunction ranges between 2.5 to $2.9 \mathrm{mmol} / \mathrm{l}(45-52 \mathrm{mg} / \mathrm{dl})$ (Fig. 1).

The greater variability of glycaemic thresholds for cognitive dysfunction $(2.5-2.9 \mathrm{mmol} / \mathrm{l})$ as compared to those for release of counterregulatory hormones and generation of symptoms, most likely reflects the different techniques used to assess brain function during hypoglycaemia. For example, in several studies a battery of neuropsychological tests has been used to explore cognitive function. Since there is no standardized neuropsychological test battery, many researchers have set up their own battery covering major mental abilities which are known to be affected by hypoglycaemia such as pattern recognition, memory, attention, psychomotor function and information processing. The results have often been reported as sum of Z-scores to give an index of overall cognitive function [2]. In contrast, in other studies, just a single cognitive function test has been employed. The most used is the four-choice reaction time [3,4]. Finally, in other studies, cognitive function has been assessed by employing brain evoked potentials. Among these, the P300 potential has usually been used because its changes during hypoglycaemia are considered to be a sensitive indicator of cognitive dysfunction [5]. The methodological limitations of using these techniques

Corresponding author: G. B. Bolli, M. D., Professor of Metabolism, University of Perugia, Di. M. I.S. E. M., Via E. Dal Pozzo, I-06126 Perugia, Italy

Abbreviations: IDDM, Insulin-dependent diabetes mellitus. have been recently reported by Heller and Macdonald [6] in their excellent review on cognitive function testing during hypoglycaemia.

To date there is good agreement that the glycaemic thresholds for activation of counterregulation and initiation of awareness of hypoglycaemia shift to lower plasma glucose concentrations following antecedent hypoglycaemia. This has been demonstrated repeatedly after experimentally induced hypoglycaemia both in non-diabetic subjects [7-9] and in patients with insulin-dependent diabetes mellitus (IDDM) [10], and in the clinical setting in intensively insulin-treated patients who experience frequent and recurrent episodes of hypoglycaemia [3-5, 11-13] and in patients with insulinoma $[14,15]$. However, there is no agreement that such a shift occurs with the glycaemic thresholds for cognitive dysfunction $[3,4,8-13,15]$.

The issue of whether or not glycaemic thresholds for cognitive function also shift to lower plasma glucose concentrations is clinically relevant. In fact, the downward shifting of glycaemic thresholds for counterregulation and awareness of hypoglycaemia might have deleterious consequences if cognitive dysfunction did not shift as well, since cognitive dysfunction would then precede the appearance of symptoms rendering subjects unable to take appropriate measures to promptly correct hypoglycaemia (i.e. eating). However, the glycaemic thresholds for cognitive dysfunction following hypoglycaemia have been shown to shift as do those of counterregulation and symptoms in some studies, but not in others.

Most of the studies using either a battery of neuropsychological tests or the P300 potential describe a downward shift in glycaemic thresholds for cognitive dysfunction following antecedent hypoglycaemia even though all these studies are remarkably different with regard to both the duration and the number of hypoglycaemic episodes, the interval period of euglyca- 


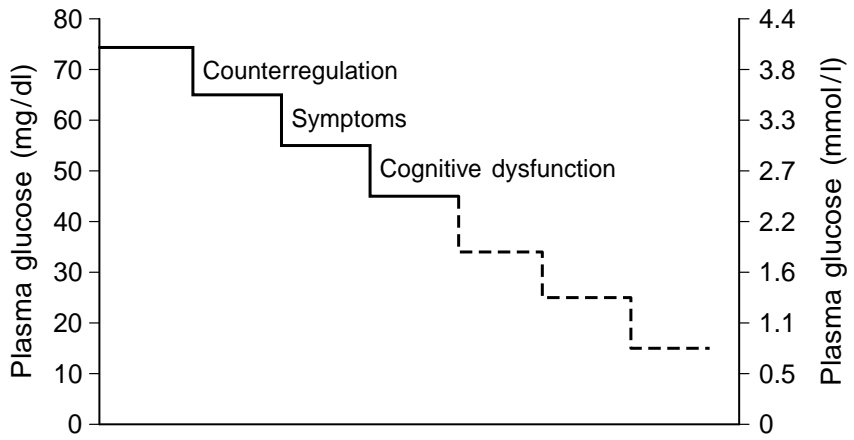

Fig. 1. Glycaemic thresholds for counterregulation, symptoms and cognitive dysfunction in non-diabetic subjects during a hyperinsulinaemic hypoglycaemic stepped clamp

emia preceding the assessment of responses, and the subjects studied. For example, in the insulinoma patients studied by Mitrakou et al. [15], and in intensively insulin-treated IDDM patients $[5,11,13,16]$ antecedent hypoglycaemia was recurrent. In contrast, a single episode of hypoglycaemia lasting $56 \mathrm{~h}$, was induced in non-diabetic subjects in the study by Boyle et al. [9], whereas other studies induced only one episode of hypoglycaemia for only $2 \mathrm{~h}[8,17]$. Despite these differences, all these studies do show at least some degree of downward shifting in glycaemic thresholds for cognitive dysfunction. However, some studies do not fully support these conclusions although a battery of neuropsychological tests was used [10, 18, 19]. However, technical and experimental objections can be raised for each of those. For example, the sample size was small in the study by Widom et al. [18], whereas no information on awareness of hypoglycaemia in diabetic patients with good glycaemic control was reported by Draelos et al. [19]. Dagogo-Jack et al. [10] carried out the lowest hypoglycaemic step only at $2.8 \mathrm{mmol} / \mathrm{l}$ $(50 \mathrm{mg} / \mathrm{dl})$, i. e. most likely a glycaemic level not low enough to ascertain cognitive dysfunction following antecedent hypoglycaemia. Notably, in a recent study where a $2 \mathrm{~h}$ episode of hypoglycaemia induced the previous night did not affect either counterregulation or symptoms the next morning, the glycaemic thresholds for cognitive dysfunction were not affected [20]. However, greater glycaemic thresholds for release of counterregulatory hormones, generation of symptoms and onset of cognitive dysfunction were observed after two or three episodes of hypoglycaemia [20]. This observation is in line with the concept that the glycaemic thresholds of responses of hormones, symptoms and cognitive dysfunction concordantly shift after antecedent hypoglycaemia.

In contrast to the studies using a battery of neuropsychological tests, the studies employing only one test, i.e. the four-choice reaction time test [3, 4], have repeatedly found no effects of antecedent hypoglycaemia on glycaemic thresholds for cognitive dysfunction.
One reason for these discrepancies might be that not all task performances are affected to the same degree following antecedent hypoglycaemia and that, consequently, not all of the cognitive function tests can detect the effect of antecedent hypoglycaemia. It would be necessary to establish which abilities of cognitive function are affected by antecedent hypoglycaemia and which tests are useful to measure these appropriately. Some tests (e.g. four-choice reaction time, story recall) might actually be non-selective to detect the effect of antecedent hypoglycaemia and should not be used for this purpose $[3,4,9,16]$. In contrast, other tests (e.g. trail making part B, delayed non-match to sample, interference subtest from the Stroop test) seem to be useful $[8,9,11,16]$. Finally, a reasonable comment is that a battery of neuropsychological tests should explore cognitive function more globally than a single test, and would therefore be more helpful in establishing the effects of antecedent hypoglycaemia.

From a clinical standpoint, the downward shift of glycaemic thresholds for cognitive dysfunction following antecedent hypoglycaemia does not reduce the risk of severe hypoglycaemia in IDDM patients, in contrast to what one would expect if this phenomenon were considered as adaptive [21]. It is plausible that in unaware IDDM patients plasma glucose concentrations may fall below $3.0 \mathrm{mmol} / \mathrm{l}(54 \mathrm{mg} / \mathrm{dl})$ without generating symptoms. At this plasma glucose level, cognitive function is still preserved and continues to be preserved at a plasma glucose level of $2.5 \mathrm{mmol} / \mathrm{l}(45 \mathrm{mg} / \mathrm{dl})$. However, if plasma glucose levels drop further, cognitive failure occurs as a consequence of severe neuroglycopenia. Note that in unaware IDDM patients the magnitude of symptoms is also markedly reduced in addition to the elevated thresholds (i.e. need for greater than normal plasma glucose concentration to evoke responses). This means that even in the case of some symptoms preceding the onset of cognitive dysfunction during hypoglycaemia, this is not of appreciable help because the symptoms are barely sensed by the patient. However, this scenario is only speculative because for ethical reasons most of the studies have generated plasma glucose concentrations not lower than $2.2 \mathrm{mmol} / \mathrm{l}$, and it is not known what is going on below this value. For example, it might well be that below $2.2 \mathrm{mmol} / \mathrm{l}$ plasma glucose level, in unaware IDDM patients thresholds for cognitive function no longer shift downwards, whereas those of symptoms do. In other words, during progressive decreases of plasma glucose to severe hypoglycaemia, cognitive dysfunction might occur before onset of symptoms. At this point, the late appearance of symptoms in the setting of brain dysfunction is of no help for the patient. Indeed, Hepburn et al. [22] found autonomic activation at plasma glucose concentrations of $1.6 \mathrm{mmol} / \mathrm{l}(29 \mathrm{mg} /$ dl) in patients with hypoglycaemia unawareness. 


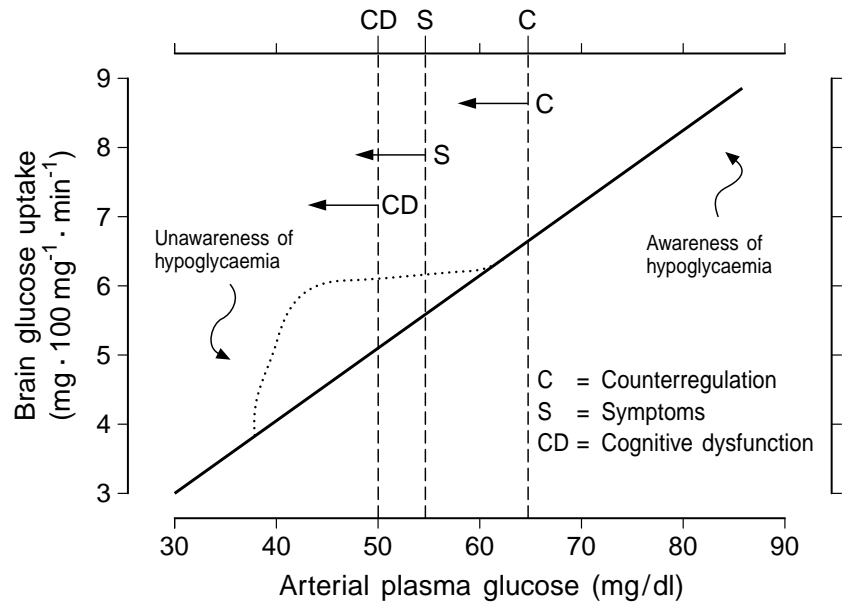

Fig. 2. Correlation between plasma glucose concentration and brain glucose uptake in non-diabetic awareness subjects (solid line [data from 21]) and in IDDM patients with hypoglycaemia unawareness (broken line [hypothetical data]). Note that at the same hypoglycaemic level of $2.7 \mathrm{mmol} / \mathrm{l}(50 \mathrm{mg} / \mathrm{dl})$ brain glucose uptake is preserved in IDDM patients with hypoglycaemia unawareness [15]. Consequently, glycaemic thresholds for counterregulation, symptoms and cognitive dysfunction are shifted to lower hypoglycaemic levels (arrows). The extent to which this mechanism provides a clinical protection is probably limited to a very narrow range of glycaemia of $0.6-0.8 \mathrm{mmol} / \mathrm{l}(10-15 \mathrm{mg} / \mathrm{dl})$ and is no longer operative below $2.2 \mathrm{mmol} / \mathrm{l}(40 \mathrm{mg} / \mathrm{dl})$, as indicated in this section by the steep fall of the broken line. Thus, outside the "apparent protective window" severe neuroglycopenia occurs

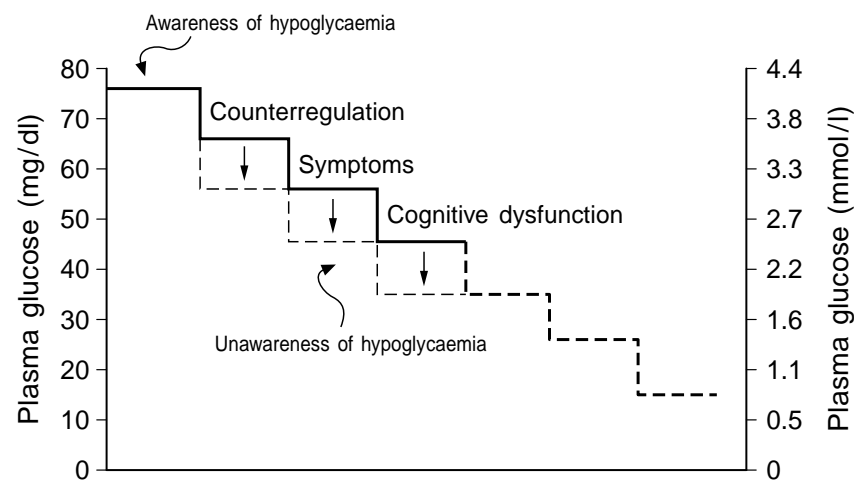

Fig.3. Glycaemic thresholds for counterregulation, symptoms and cognitive dysfunction in non-diabetic subjects (solid line) and in IDDM with hypoglycaemia unawareness (broken line)

Clearly, it is not possible to repeat these experiments in a controlled fashion. Therefore, this is and will probably remain a simple hypothesis.

The physiological mechanisms responsible for these changes in glycaemic thresholds have not been firmly established. However, preserved blood to brain glucose transport during hypoglycaemia may play a crucial role. Normally, there is a linear correlation between the fall of blood glucose and brain glucose uptake [23]. Thus, glucose transport from blood into the brain can become the limiting step if plasma glucose concentration falls to hypoglycaemic levels of approximately $2.0 \mathrm{mmol} / 1$ [24]. However, Boyle et al. [6] have demonstrated preserved brain glucose uptake in nondiabetic subjects after $56 \mathrm{~h}$ of mild hypoglycaemia [3] and in IDDM patients with hypoglycaemia unawareness [25], confirming previous data from animal studies [26, 27]. This mechanism of preserved brain glucose uptake in the face of hypoglycaemic levels would explain why all of the physiological responses to hypoglycaemia including cognitive dysfunction are shifted to lower plasma glucose levels as an effect of antecedent hypoglycaemia (Fig. 2). However, it is reasonable to think that there is a glycaemic threshold (2.5-2.0 mmol/l?) at which preserved brain glucose uptake fails to support a normal neuronal metabolism suddenly producing a picture of severe neuroglycopenia. Activation of symptoms at this point would nearly coincide with onset of severe neuroglycopenia, as indirectly suggested by the study of Hepburn at al. [22]. Additional, indirect support for this view derives from a clinical observation of patients with insulinoma [15]. These patients maintain an apparently normal cognitive function at plasma glucose values of approximately $2.2 \mathrm{mmol} / \mathrm{l}(40 \mathrm{mg} / \mathrm{dl})$, both in the clinical as well as in the experimental situation [15]. However, it is well-known that, should their plasma glucose concentration drop by $0.2-0.3 \mathrm{mmol} / \mathrm{l}(4-6 \mathrm{mg} / \mathrm{dl})$, they suddenly experience severe neuroglycopenia as if the previous "brain protection" was suddenly lost.

Preserved brain glucose uptake might not be the unique mechanism responsible for the changes in glycaemic thresholds after antecedent hypoglycaemia. Indeed, Davis et al. [28] have proposed that cortisol plays a role in the pathogenesis of deficient counterregulation and blunted hormonal responses following antecedent hypoglycaemia. In that study, the authors demonstrated that increased plasma cortisol levels during two episodes of $2 \mathrm{~h}$ of experimental hypoglycaemia induced the day before, reduced the counterregulatory responses during an episode of hypoglycaemia the next day. These findings were confirmed in a study by Pampanelli et al. [29] who established the role of cortisol on counterregulation, symptoms and cognitive function. Pampanelli et al. concluded that cortisol responses to antecedent hypoglycaemia plays a role in reducing the adrenaline, glucagon and autonomic responses during subsequent hypoglycaemia, whereas neuroglycopenic symptoms and cognitive function are mediated by hypoglycaemia "per se". Most likely, both these mechanisms play a role in the process of shifting the glycaemic thresholds after antecedent hypoglycaemia. To date, enhanced blood to brain glucose transport has been demonstrated only after chronic antecedent hypoglycaemia, whereas episodes occurring in the clinical setting are usually short and recurrent. Therefore, cortisol might first initiate the vicious cycle of hypoglycaemia 
unawareness by affecting counterregulation and autonomic response, whereas hypoglycaemia "per se" (via enhanced blood to brain glucose transport?) might induce functional adaptation of brain following short-term recent antecedent hypoglycaemia and perpetuate this cycle in the long-term.

In conclusion, the glycaemic thresholds for cognitive dysfunction shift to lower plasma glucose levels after antecedent hypoglycaemia as do those for counterregulation and symptoms of hypoglycaemia (Fig.3), but the clinical protection is limited over a span of plasma glucose levels of no more than $0.6-0.8 \mathrm{mmol} / \mathrm{l}$ $(10-15 \mathrm{mg} / \mathrm{dl})$. This mechanism of "compensation" is apparently only protective, i.e. adaptive [21]. In fact, it is dangerous because it predisposes patients to severe hypoglycaemia and, for that reason, it should be avoided by preventing recurrent hypoglycaemia in the real life of patients with diabetes [11].

\section{References}

1. Mitrakou A, Ryan C, Veneman Tet al. (1991) Hierarchy of glycemic thresholds for counterregulatory hormone secretion, symptoms, and cerebral dysfunction. Am J Physiol 260: E67-E74

2. Fanelli C, Pampanelli S, Epifano L et al. (1994) Relative role of insulin and hypoglycaemia on induction of neuroendocrine responses to, symptoms of, and deterioration of cognitive function in hypoglycaemia in male and female humans. Diabetologia 37: 797-807

3. Cranston I, Lomas J, Maran A, Macdonald I, Amiel S (1994) Restoration of hypoglycaemia awareness in patients with long-duration insulin dependent diabetes. Lancet 344 : 283-287

4. Maran A, Lomas J, Macdonald IA, Amiel SA (1995) Lack of preservation of higher brain function during hypoglycaemia in patients with intensively-treated IDDM. Diabetologia 38: 1412-1418

5. Jones TW, Borg WP, Borg MA et al. (1997) Resistance to neuroglycopenia: an adaptative response during intensive insulin treatment in IDDM. J Clin Endocrinol Metab 82: 1713-1718

6. Heller SR, Macdonald IA (1996) The measurement of cognitive function during acute hypoglycemia: experimental limitations and their effect on the study of hypoglycemia unawareness. Diabet Med 13: 607-615

7. Heller SR, Cryer PE (1991) Reduced neuroendocrine and symptomatic responses to subsequent hypoglycemia after one episode of hypoglycemia in nondiabetic humans. Diabetes 40: 223-226

8. Veneman T, Mitrakou A, Mokan M, Cryer P, Gerich J (1993) Induction of hypoglycemia unawareness by asymptomatic nocturnal hypoglycemia. Diabetes 42: 1233-1237

9. Boyle PJ, Nagy RJ, O’Connor AM, Kempers SF, Yeo RA, Qualls C (1994) Adaptation in brain glucose uptake following recurrent hypoglycemia. Proc Natl Acad Aci USA 91: 9352-9356

10. Dagogo-Jack SE, Craft S, Cryer PE (1993) Hypoglycemiaassociated autonomic failure in insulin-dependent diabetes mellitus. J Clin Invest 91: 819-828

11. Fanelli CG, Epifano L, Rambotti AM et al. (1993) Meticulous prevention of hypoglycemia normalizes the glycemic thresholds and magnitude of most of neuroendocrine responses to, symptoms of, and cognitive function during hypoglycemia in intensively treated patients with short-term IDDM. Diabetes 42: 1683-1689

12. Dagogo-Jack S, Rattarasarn C, Cryer PE (1994) Reversal of hypoglycemia unawareness, but not defective glucose counterregulation, in IDDM. Diabetes 43: 1426-1434

13. Mokan M, Mitrakou A, Veneman T et al. (1994) Hypoglycemia unawareness in IDDM. Diabetes Care 17: 1397-1403

14. Maran A, Taylor J, Macdonald IA, Amiel SA (1991) Evidence for reversibility of defective counterregulation in a patient with insulinoma. Diabet Med 9: 765-768

15. Mitrakou A, Fanelli C, Veneman T et al. (1993) Reversibility of unawareness of hypoglycemia in patients with insulinoma. N Engl J Med 329: 834-839

16. Fanelli CG, Paramore D, Hershey T, Terkamp C, Craft S, Cryer P (1996) Impact of nocturnal hypoglycemia on hypoglycemic cognitive dysfunction the following morning in IDDM. Diabetes [Suppl 1] 55A: 198 (Abstract)

17. Mellman MJ, Davis M, Brisman M, Shamoon H (1994) Effect of antecedent hypoglycemia on cognitive function and on glycemic thresholds for counterregulatory hormone secretion in healthy humans. Diabetes Care 17: 183-188

18. Widom B, Simonson DC (1990) Glycemic control and neuropsychologic function during hypoglycemia in patients with insulin-dependent diabetes mellitus. Ann Intern Med 112: 904-912

19. Draelos MT, Jacobson AM, Weinger K et al. (1995) Cognitive function in patients with insulin-dependent diabetes mellitus during hyperglycemia and hypoglycemia. Am J Med 98: 135-144

20. Fanelli C, Pampanelli S, Ciofetta M et al. (1997) Effect of duration of recent antecedent hypoglycemia on responses to subsequent hypoglycemia in humans. Diabetologia 40 [Suppl 1] A235: 923 (Abstract)

21. Cryer PE (1985) Does central nervous system adaptation to antecedent glycemia occur in patients with insulin-dependent diabetes mellitus? Ann Intern Med 103: 284-286

22. Hepburn DA, MacLeod KM, Frier BM (1993) Physiological, symptomatic and hormonal responses to acute hypoglycaemia in type 1 diabetic patients with autonomic neuropathy. Diabet Med 10: 940-949

23. Cryer PE, Gerich JE (1986) Glucose counterregulation, hypoglycemia, and intensive insulin therapy in diabetes mellitus. N Engl J Med 313: 232-241

24. Gruetter R, Novotny EJ, Boulware SD et al. (1992) Direct measurement of brain glucose concentrations in humans by ${ }^{13} \mathrm{C}$ NMR spectroscopy. Proc Natl Acad Sci USA 89: 1109-1112

25. Boyle PJ, Kempers SK, O'Connor AM, Nagy RJ (1995) Brain glucose uptake and unawareness of hypoglycemia in patients with insulin-dependent diabetes mellitus. N Engl J Med 333: 1726-1731

26. McCall AL, Fixman LB, Fleming N, Tornhein K, Chick W, Ruderman NB (1985) Chronic hypoglycemia increases brain glucose transport. Am J Physiol 251: E442-E447

27. Pelligrino DA, Segil LJ, Albrecht RF (1990) Brain glucose utilization and transport and cortical function in chronic vs acute hypoglycemia. Am J Physiol 259: E729-E735

28. Davis SN, Shavers C, Costa F, Mosqueda-Garcia R (1996) Role of cortisol in the pathogenesis of deficient counterregulation after antecedent hypoglycemia in normal humans. J Clin Invest 98: 680-691

29. Pampanelli S, Lalli C, Del Sindaco P et al. (1997) Effect of recent, antecedent hypoglycemia and responses of cortisol per se, on responses to subsequent hypoglycemia in humans. Diabetologia 40 [Suppl 1] A27: 99 (Abstract) 